\title{
DETERMINATION OF THE EFFECT OF ZEOLITE AND ORGANIC ACID MIXTURE SUPPLEMENTATION IN THE LAYER DIET ON PERFORMANCE AND EGG QUALITY USING GREY RELATIONAL ANALYSIS METHOD
}

\author{
Aycan Mutlu YAĞANOĞLU1*, Mehmet TOPAL ${ }^{2}$ \\ ${ }^{1}$ Atatürk University, Faculty of Agriculture, Department of Animal Science, 25240, Erzurum, Turkey \\ ${ }^{2}$ Amasya University, Faculty of Medicine, Department of Biostatistics, 05200, Amasya, Turkey
}

\begin{abstract}
Grey system theory is a method used when the assumptions of homogeneity of variances in the application of parametric statistical methods of analysis, the assumption that the distribution of data to be applied is appropriate to the normal distribution and that it is, for example, of sufficient size. Grey relational analysis is one of the subtitles of the grey system theory and it is a method of grading, classification and decision making in the data set using the Grey Relation Coefficient (GIA). In this study, the effects of addition of zeolite, organic acid and zeolite-organic acid added to the rations of twenty-four Lohmann LSL type white-laying hens at 28 weeks of age on the quality and performance of eggs were examined. Grey relational analysis was applied to egg quality and performance criteria. It was found that the highest quality eggs were added with organic acid (P) additions to the chicken rations (P6, P3, P1), and the $\mathrm{K} 1$ in the control group and the $(\mathrm{Z}+\mathrm{P}) 1$ sample in which the zeolite and organic acid additives were applied together were also found in the quality egg group. In terms of quality, middle class egg samples were determined to be zeolite additive group and low quality egg group was found to be control and zeolite + organic acid added group.
\end{abstract}

Keywords: Grey relational analysis, Performance, Egg quality, Zeolit, Organic acid

*Corresponding author: Atatürk University, Faculty of Agriculture, Department of Animal Science, 25240, Erzurum, Turkey

E mail: myagan@atauni.edu.tr (A.M. YAĞANOĞLU)

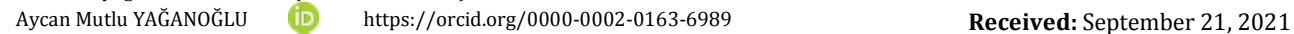

Mehmet TOPAL

https://orcid.org/0000-0001-8836-5773

Accepted: October 07, 2021

Published: January 01, 2022

Cite as: Yağanoğlu AM, Topal M. 2022. Determination of the effect of zeolite and organic acid mixture supplementation in the layer diet on performance and egg quality using grey relational analysis method. BSJ Agri, 5(1): 16-20.

\section{Introduction}

The main purpose in animal production is to provide high income from farm animals in line with low costs (Kumlu 1999). The animals with the highest values in terms of productivity should be weeded out and the next generations should be formed from their offspring. In order to carry out the animal breeding studies successfully, it is necessary to obtain the data of the breeder candidates and their relatives and to determine the breeding values with the lowest error. The comparison of breeding values of individuals in line with the information obtained from different sources is possible with the use of the selection index. In animal breeding studies, the selection index value is one of the most important parameters used for the selection of animals.

In recent years, as a result of developments in mathematics, statistics and information technologies, different variance estimation methods such as analysis of variance (ANOVA), maximum likelihood (ML) and restricted maximum likelihood (REML) have been developed. Henderson (1984), with the spread of simple algorithms based on mixed model equations, the REML method introduced by Patterson and Thompson (1971) has become the most widely used method for estimating the variance elements of mixed models in animal breeding.

Grey system theory is one of the ideal methods that can be applied to the solution of these problems in cases where the information is little or discrete, as well as when the information is too much or uncertain. It is also an approach to multivariate statistics that helps to model uncertainties whose distribution is unknown and for which sufficient data set cannot be obtained (Üstünışık, 2007).

Mammedova and Keskin (2011) found that by using the characteristics of the cows' movement, whether they are active and the time elapsed after the last estrus, using the fuzzy logic method, the estrus can be detected correctly, and the estrus is detected at a rate that can be considered quite high, such as $98 \%$.

Wade et al. (1998), in their breeding study, stated that as a result of the fuzzy model created by using the milk yield, birth interval and age parameters of the animal, it is easy to decide on the selection of animals with low milk yield, long birth interval and high age, but with higher milk yield and birth interval. They stated that it 
would not be easy to make a decision for tall and very old animals. As a result, they stated that the method applied to determine which animal or animals will be removed from the herd is beneficial for animal husbandry.

According to Morag et al. (2001) developed a decision support system that determines the amount of concentrated feed that should be added to the rations of farm animals individually according to the performance (milk yield and body weight) of the farm animals, using fuzzy logic. The researchers, who showed that the decision support systems created using fuzzy logic can be used practically, stated that there is a $10 \%$ difference between the decisions made by the Decision Support Systems (DSS) and the decisions made by the expert, and this is not important.

\section{Material and Methods}

\subsection{Animal Materials}

The animal material of the study consisted of 24 Lohmann LSL type white layer hens aged 28 weeks, raised in the Poultry Branch of Atatürk University, Faculty of Agriculture, Agricultural Research and Extension Center.

\subsection{Statistical Analysis}

\subsubsection{Grey relational analysis}

Grey relational analysis is considered to indicate that black does not have information, white has information completely, and grey indicates the degree of information between black and white. In other words, it is based on the rule that some information is known and some is not known in the grey system. In the white system, the interrelationships within the system are certain, but not in the grey system (Tosun 2006).

Grey relational analysis is one of the sub-titles of grey modelling. This analysis method is a method for determining the degree of relationship between each factor in a grey system and the compared factor (reference series) series. Each factor is defined as an array (row or column). The degree of influence between the factors is called the grey relational degree (Üstünışık, 2007).

The steps of the grey relational analysis method are as follows;

Step 1: Formulate $\mathrm{n}$ reference series (Deng 1989) (equation 1).

$x_{0}=\left(x_{0}(1), x_{0}(2), x_{0}(3), \ldots \ldots x_{0}(n)\right)$

Step 2: Normalization of data.

Normalization in case of "higher is better"; Kuo et al. (2008) (equation 2).

$x_{i}(k)=\frac{x_{i}^{0}(k)-\min x_{i}^{0}(k)}{\max x_{i}^{0}(k)-\min x_{i}^{0}(k)}$

Normalization in case of "lower is better" (equation 3); $x_{i}(k)=\frac{\max x_{i}^{0}(k)-x_{i}^{0}(k)}{\max x_{i}^{0}(k)-\min x_{i}^{0}(k)}$

Normalization in case of "better than ideal value" (equation 4);

$x_{i}(k)=1-\frac{\left|x_{i}^{0}(k)-x^{0}\right|}{\max x_{i}^{0}(k)-x^{0}}$

Step 3: The $\mathrm{m}$ series to be compared with the $x^{0}$ series are defined as follows; Zhu and Hao (2009) (equation 5).

$x_{i}=\left(x_{i}(1), x_{i}(2), x_{i}(3), \ldots \ldots x_{0}(n)\right) \mathrm{i}=1,2, \ldots \ldots \mathrm{m}$

Step 4: $\mathrm{k}, \mathrm{k}$ in $\mathrm{n}$ series. $\varepsilon\left(x_{0}(k), x_{i}(\mathrm{k})\right), \mathrm{k}$. The grey at the point is the relational coefficient and is represented by the formula below. Mao, et al. (2010) (equation 6).

$\varepsilon\left(x_{0}(k), x_{i}(\mathrm{k})\right)=\frac{\Delta_{\min }+\xi \Delta_{\max }}{\Delta_{0 i}(k)+\xi \Delta_{\max }}$

$\Delta_{0 i}(k)=\left|x_{0}(k)-x_{j}(k)\right|$

$\Delta_{\text {min }}=\min _{j} \min _{k}\left|x_{0}(k)-x_{j}(k)\right|$

$\Delta_{\max }=\max _{j} \max _{k}\left|x_{0}(k)-x_{j}(k)\right|$

Step 5: grey relational degree coefficients are calculated; (Wu, 2007) (equation 7).

$\gamma\left(x_{0}, x_{i}\right)=\frac{1}{n} \sum_{k=1}^{n} \varepsilon\left(x_{0}(k), x_{i}(\mathrm{k})\right)$

\section{Results}

Correlation coefficients (Table 1) are examined, haugh unit and white index (WI) (0.798), daily feed consumption (DFC) and egg production (EP) (0.728), daily feed consumption (DFC) and feed conversion ratio (FCR) (0.694) ), yellow index (YI) and white index (WI) (0.606) and shape index (SI) and white index (WI) (0.520) were found to have a statistically significant correlation in the linear direction can be said to be affected. Shell thickness (KK) with haugh unit (0.468), shell weight (KA) with shell thickness (KK) (0.464), haugh unit with yellow index (SI) (0.445), white index (AI) with shell thickness (KK) A statistically significant linear relationship was found between $(0.425)$ and shape index (SI) and crustal thickness (KK) (0.410), and an increase in any of these variables causes an increase in the other.

\subsection{Results of Grey Relational Analysis Method}

Table 2 is examined, when the averages of grey relationship degrees of egg quality and performance characteristics are taken into account, the quality and performance criteria for the sample data set are Haugh unit (0.736), shape index (0.645), feed conversion ratio (0.589), breaking strength (0.548), in order of importance egg production (0.546), egg weight (0.537), yellow index (0.520), white index (0.517), shell weight (0.508), daily feed consumption (0.504), shell thickness (0.489) are listed as. Among these variables, the grey 


\section{Black Sea Journal of Agriculture}

correlation coefficient averages of the Haugh unit, shape index and feed conversion ratio were found to be higher than the general average of the grey correlation coefficients (0.558), while the average of the other variables was found to be smaller than the general average. Therefore, these variables (Haugh unit, shape index and feed conversion ratio) can be taken as important quality characters in determining egg quality criteria.

Table 1. Correlation coefficients between quality and performance parameters

\begin{tabular}{|c|c|c|c|c|c|c|c|c|c|c|c|}
\hline & EW & FCR & EP & DFC & BS & SI & ST & SW & WI & YI & Haugh \\
\hline EW & 1 & & & & & & & & & & \\
\hline FCR & $-0,229$ & 1 & & & & & & & & & \\
\hline EP & $-0,095$ & 0,126 & 1 & & & & & & & & \\
\hline DFC & 0,102 & $0,694^{* *}$ & $0,728^{* *}$ & 1 & & & & & & & \\
\hline BS & 0,091 & 0,150 & $-0,367$ & $-0,103$ & 1 & & & & & & \\
\hline SI & 0,246 & $-0,285$ & $-0,024$ & $-0,142$ & 0,092 & 1 & & & & & \\
\hline ST & 0,341 & 0,117 & $-0,365$ & $-0,062$ & 0,236 & $0,410^{*}$ & 1 & & & & \\
\hline SW & 0,213 & $-0,131$ & $-0,207$ & $-0,151$ & 0,264 & 0,020 & $0,464^{*}$ & 1 & & & \\
\hline WI & 0,252 & 0,021 & 0,068 & 0,126 & $-0,165$ & $0,520^{* *}$ & $0,425^{*}$ & 0,125 & 1 & & \\
\hline YI & 0,031 & $-0,111$ & $-0,106$ & $-0,128$ & $-0,089$ & 0,213 & 0,291 & 0,002 & $0,606^{* *}$ & 1 & \\
\hline Haugh & 0,289 & 0,196 & 0,188 & 0,337 & $-0,162$ & 0,328 & $0,468^{*}$ & $-0,014$ & $0,798^{* *}$ & $0,445^{*}$ & 1 \\
\hline
\end{tabular}

Table 2. Grey relation coefficients according to quality and performance criteria

\begin{tabular}{|c|c|c|c|c|c|c|c|c|c|c|c|}
\hline Group & EW & FCR & EP & DFC & BS & SI & ST & SW & WI & YI & Haugh \\
\hline K1 & 0.754 & 0.555 & 0.452 & 0.455 & 0.369 & 0.857 & 0.495 & 0.446 & 0.666 & 1.000 & 0.914 \\
\hline K2 & 0.486 & 0.521 & 0.576 & 0.429 & 0.401 & 0.462 & 0.432 & 0.476 & 0.407 & 0.333 & 0.525 \\
\hline K3 & 0.449 & 0.603 & 0.655 & 0.449 & 0.333 & 0.750 & 0.398 & 0.422 & 0.453 & 0.408 & 0.655 \\
\hline K4 & 0.368 & 0.333 & 0.559 & 0.367 & 0.486 & 0.750 & 0.451 & 0.429 & 0.337 & 0.379 & 0.644 \\
\hline K5 & 0.772 & 0.619 & 0.528 & 0.437 & 0.486 & 0.600 & 0.495 & 0.539 & 0.565 & 0.472 & 0.761 \\
\hline K6 & 0.368 & 0.596 & 0.792 & 0.452 & 0.391 & 0.462 & 0.357 & 0.351 & 0.643 & 0.548 & 0.887 \\
\hline Z1 & 0.462 & 0.737 & 0.792 & 0.456 & 0.484 & 0.500 & 0.415 & 0.449 & 0.590 & 0.446 & 0.832 \\
\hline $\mathrm{Z} 2$ & 0.600 & 0.608 & 0.559 & 0.445 & 0.484 & 1.000 & 0.415 & 0.394 & 0.445 & 0.475 & 0.752 \\
\hline Z3 & 0.600 & 0.471 & 0.352 & 0.533 & 0.484 & 0.375 & 0.750 & 0.474 & 1.000 & 0.651 & 0.995 \\
\hline $\mathrm{Z} 4$ & 0.368 & 0.348 & 0.792 & 0.333 & 0.540 & 0.750 & 0.472 & 0.574 & 0.699 & 0.650 & 0.929 \\
\hline Z5 & 0.506 & 0.640 & 0.404 & 0.591 & 0.544 & 0.857 & 0.451 & 0.393 & 0.352 & 0.479 & 0.468 \\
\hline Z6 & 0.333 & 0.965 & 0.371 & 1.000 & 0.615 & 0.667 & 0.333 & 0.444 & 0.333 & 0.482 & 0.333 \\
\hline P1 & 0.902 & 0.847 & 0.559 & 0.474 & 0.486 & 0.429 & 0.654 & 0.672 & 0.572 & 0.460 & 0.876 \\
\hline P2 & 0.589 & 0.532 & 0.433 & 0.483 & 0.515 & 0.333 & 0.580 & 0.476 & 0.612 & 0.737 & 1.000 \\
\hline P3 & 0.394 & 1.000 & 0.352 & 0.969 & 0.482 & 0.750 & 0.548 & 0.531 & 0.505 & 0.636 & 0.822 \\
\hline P4 & 0.479 & 0.496 & 1.000 & 0.352 & 0.599 & 0.545 & 0.451 & 0.364 & 0.468 & 0.639 & 0.823 \\
\hline P5 & 0.381 & 0.520 & 0.792 & 0.415 & 0.389 & 0.667 & 0.451 & 0.743 & 0.477 & 0.540 & 0.610 \\
\hline P6 & 0.531 & 0.851 & 0.333 & 0.834 & 0.670 & 0.667 & 0.548 & 1.000 & 0.499 & 0.489 & 0.763 \\
\hline$(\mathrm{Z}+\mathrm{P}) 1$ & 1.000 & 0.582 & 0.559 & 0.396 & 0.708 & 1.000 & 0.398 & 0.782 & 0.393 & 0.415 & 0.529 \\
\hline$(\mathrm{Z}+\mathrm{P}) 2$ & 0.506 & 0.439 & 0.458 & 0.435 & 1.000 & 0.600 & 0.432 & 0.556 & 0.545 & 0.452 & 0.656 \\
\hline$(\mathrm{Z}+\mathrm{P}) 3$ & 0.531 & 0.419 & 0.404 & 0.454 & 0.993 & 0.462 & 1.000 & 0.560 & 0.464 & 0.446 & 0.695 \\
\hline$(\mathrm{Z}+\mathrm{P}) 4$ & 0.394 & 0.342 & 0.392 & 0.448 & 0.680 & 0.857 & 0.451 & 0.427 & 0.468 & 0.466 & 0.743 \\
\hline$(\mathrm{Z}+\mathrm{P}) 5$ & 0.600 & 0.744 & 0.559 & 0.488 & 0.553 & 0.545 & 0.370 & 0.333 & 0.471 & 0.457 & 0.777 \\
\hline$(\mathrm{Z}+\mathrm{P}) 6$ & 0.522 & 0.369 & 0.432 & 0.401 & 0.455 & 0.600 & 0.383 & 0.367 & 0.446 & 0.410 & 0.679 \\
\hline Ort GRC & 0.537 & 0.589 & 0.546 & 0.504 & 0.548 & 0.645 & 0.489 & 0.508 & 0.517 & 0.520 & 0.736 \\
\hline Rank & (6) & (3) & (5) & $(10)$ & (4) & (2) & (11) & (9) & (8) & (7) & (1) \\
\hline
\end{tabular}

According to the results given in Table 3 , the best egg sample according to the grey relationship in terms of quality and performance was found organic acid (P6) added to the chicken ration, while the lowest egg sample in terms of quality and performance was the combination of zeolite and organic acid $(\mathrm{Z}+\mathrm{P})$. The difference between the grey relation degree of the best egg sample (P6) 0.653 and the grey relation degree of the lowest $(\mathrm{Z}+\mathrm{P}) 60.460$ sample in terms of quality and performance (0.653-0.460) was 0.193, which is the standard value calculated over all samples. Since the deviation is higher than $(0,172)$, we can say that there may be a difference in quality and performance between the best (P6) sample and the worst $(\mathrm{Z}+\mathrm{P}) 6$. In terms of quality and performance, five of the six samples (P1,P2,P3,P4,P5,P6) with organic acid added to the 
chicken ration $(\mathrm{P} 1, \mathrm{P} 2, \mathrm{P} 3, \mathrm{P} 4, \mathrm{P} 6)$ and six samples $(\mathrm{Z1}, \mathrm{Z2}, \mathrm{Z3}, \mathrm{P} 6)$ with zeolite added of the four $(\mathrm{Z1}, \mathrm{Z2}, \mathrm{Z3}, \mathrm{Z} 4)$, zeolite and organic acid were added for six samples $((\mathrm{Z}+\mathrm{P}) 1,(\mathrm{Z}+\mathrm{P}) 2,(\mathrm{Z}+\mathrm{P}) 3,(\mathrm{Z}+\mathrm{P}) 4,(\mathrm{Z}+\mathrm{P}) 5,(\mathrm{Z}+\mathrm{P}) 6)$ of three $((Z+P) 1,(Z+P) 2,(Z+P) 3)$ of six samples with no addition (control) $(\mathrm{K} 1, \mathrm{~K} 2, \mathrm{~K} 3, \mathrm{~K} 4, \mathrm{~K} 5, \mathrm{~K} 6)$ on the other hand, it was determined that the two $(\mathrm{K} 1, \mathrm{~K} 5)$ were higher than the general grey correlation degree average (0.558), which means that there is a ranking from best to worse (Organic) between the groups in terms of quality and performance.

Table 3. Grey relational degrees calculated over real values

\begin{tabular}{lcccc}
\hline & $\gamma_{i}$ & Rank & $S_{\gamma_{i}}$ & $\gamma_{i} \pm S_{\gamma_{i}}$ \\
\hline K1 & 0.633 & 3 & 0.218 & $0.415 \pm 0.851$ \\
K2 & 0.459 & 23 & 0.068 & $0.391 \pm 0.527$ \\
K3 & 0.507 & 21 & 0.134 & $0.373 \pm 0.641$ \\
K4 & 0.464 & 22 & 0.136 & $0.328 \pm 0.600$ \\
K5 & 0.570 & 10 & 0.111 & $0.459 \pm 0.681$ \\
K6 & 0.531 & 18 & 0.182 & $0.349 \pm 0.714$ \\
Z1 & 13 & 0.154 & $0.407 \pm 0.714$ \\
Z2 & 12 & 0.180 & $0.382 \pm 0.741$ \\
Z3 & 0.560 & 6 & 0.224 & $0.383 \pm 0.832$ \\
Z4 & 7 & 0.197 & $0.390 \pm 0.783$ \\
Z5 & 19 & 0.142 & $0.375 \pm 0.659$ \\
Z6 & 0.608 & 17 & 0.250 & $0.284 \pm 0.784$ \\
P1 & 0.587 & 4 & 0.175 & $0.455 \pm 0.805$ \\
P2 & 0.517 & 9 & 0.176 & $0.396 \pm 0.748$ \\
P3 & 0.534 & 2 & 0.221 & $0.414 \pm 0.857$ \\
P4 & 0.630 & 11 & 0.196 & $0.369 \pm 0.761$ \\
P5 & 0.572 & 15 & 0.142 & $0.402 \pm 0.686$ \\
P6 & 0.635 & 1 & 0.196 & $0.457 \pm 0.849$ \\
(Z+P)1 & 0.565 & 5 & 0.230 & $0.385 \pm 0.845$ \\
(Z+P)2 & 0.544 & 14 & 0.166 & $0.387 \pm 0.719$ \\
(Z+P)3 & 0.653 & 2 & 0.219 & $0.365 \pm 0.803$ \\
(Z+P)4 & 0.615 & 16 & 0.166 & $0.349 \pm 0.682$ \\
(Z+P)5 & 0.553 & 24 & 0.137 & $0.399 \pm 0.673$ \\
(Z+P)6 & 0.584 & 0.101 & $0.360 \pm 0.561$ \\
Mean & 0.515 & 0.172 & 0.730 \\
\hline
\end{tabular}

Comparing according to grey relationship degrees, it is stated that the sample with a grey relationship degree value close to 1 is of the best quality. The grey relationship degree ranges from 0 to 1 . A grey relationship degree close to 1 indicates that the relationship between the actual values and reference values is high, that is, close to 0 , it is low. The reference values were taken as the best quality value (1) for each variable. Accordingly, we can say that the closer the grey relation degree value is to 1 , the higher the quality of the egg, and the closer it is to 0 , the lower the quality in determining the quality egg using the grey relational analysis method. Accordingly, in Table 6, when egg samples are compared according to the grey relation degrees calculated by considering the real data set, the best quality eggs are P6 (0.653), P3 (0.635), K1 (0.633), P1 (0.630), (Z+P)1 (0.615), Z3 (0.608), Z4(0.587), (Z+P)3 (0.584), P2 (0.572), K5 (0.570), P4 (0.565), Z2 (0.561), $\mathrm{Z} 1$ (0.560) , (Z+P)2 (0.553), P5 (0.544), (Z+P)5 (0.536), Z6 (0.534), K6 (0.531), Z5 (0.517) , (Z+P)4 (0.515) , K3 (0.507), K4 (0.464), K2 (0.459) and (Z+P)6 (0.460) were determined respectively. Therefore, considering all the parameters examined, it can be stated that the best egg belongs to the P6 sample, and the lowest value egg belongs to the $(\mathrm{Z}+\mathrm{P}) 6$ sample. At the same time, the grey relationship degrees of P6, P3, K1, P1, (Z+P)1, Z3, Z4, $(\mathrm{Z}+\mathrm{P}) 3, \mathrm{P} 2, \mathrm{~K} 5, \mathrm{P} 4, \mathrm{Z} 2$ and $\mathrm{Z} 1$ eggs are higher than the average (0.558) indicates that the eggs are of acceptable quality. However, when comparing the grey relation degree values between each egg sample, the difference between the grey relation degree values is significantly higher, which reveals the difference between the two eggs more clearly. It can be said that the difference between the grey correlation degree values of P6 and P3 egg samples is very low $(0.653-0.635=0.018)$, so P6 is better than P3, but the quality difference between P6 and P3 egg samples is not significant. On the other hand, the high difference $(0.653-0.460=0.193)$ between the grey correlation grade values of P6 and $(\mathrm{Z}+\mathrm{P}) 6$ egg samples indicates that the quality grade between $\mathrm{P} 6$ and $(\mathrm{Z}+\mathrm{P}) 6$ eggs is significant and that P6 $(\mathrm{Z}+\mathrm{P}) 6$ indicates better quality. 


\section{Black Sea Journal of Agriculture}

\section{Conclusion}

The gray relational analysis method is a suitable method for selecting quality characters, especially for selecting or comparing individual samples with small sample sizes.

\section{Author Contributions}

AMY; developed, organized, analyzed and interpreted the data and wrote the manuscript. MT; initiated the research idea, supervised the research, suggested the research methods, structured the paper and edited the manuscript.

\section{Ethical Approval}

Ethics committee approval required for this study was obtained from Atatürk University Experimental Animals Local Ethics Committee Presidency (decision no. 10/189, dated 30.12.2015).

\section{Conflict of Interest}

The authors declared that there is no conflict of interest.

\section{References}

Deng JJ. 1989. Indroduction to Grey System Theory. J Grey Syst, 1(1): 1-24.

Henderson CR. 1984. Application of linear models in animal breeding. Henderson CR. University of Guelph Press, Guelph: Ontorio, Canada, 1st ed., pp. 461.

Kumlu S. 1999. Hayvan ıslahı. Türkiye Damızlık Sığır Yetiştiricileri Merkez Birliği Yayınları, Ankara, Türkiye 1. baski, ss. 296.

Kuo Y, Yang T, Huang GW. 2008. The use of grey relational analysis in solving multiple attribute decision-making problems. Comput Indust Engin, 55: 80-93.

Mao PL, Liu J, Wang C Hu. 2010. A study on gray relational analysis of many factor weights in tobacco leaves classification. Adv Mater Res, 139-141: 1728-1731.

Memmedoca N, Keskin İ. 2009. Hayvancılıkta bulanık mantık uygulamaları. Selçuk Üniv Tarım Gıda Bilim Derg, 23(47): 8995.

Morag I, Edan Y, Maltz E. 2001. An individual feed allocation decision support system for the dairy farm. J Agric Eng Res, 79(2): 167-176.

Patterson HD, Thompson R. 1971. Recovery of interblock information when block sizes are unequal. Biometrica, 58: 545-554.

Tosun N. 2006. Determination of optimum parameters for multi-performance characteristics in drilling by using grey relational analysis. Inter J Advan Manufact Technol, 28: 450455.

Üstünışık NZ. 2007. Türkiye'deki iller ve bölgeler bazında sosyo-ekonomik gelişmişlik sıralaması araştırması: Gri ilişkisel analiz yöntemi ve uygulaması. Yüksek Lisans Tezi, Gazi Üniversitesi, Fen Bilimleri Enstitüsü, Ankara, Türkiye, pp. 257.

Wade KM, Lacroix R, Strasser M. 1998. Fuzzy logic membership values as a ranking tool for breeding purposes in dairy cattle. In: Proceedings of the 6th World Congress on Genetics Applied to Livestock Production, January 11-16, Armidale, Australia, 27: 433-436.

$\mathrm{Wu} \mathrm{CH} .2007$. On the application of grey relational analysis and RIDIT analysis to likert scale surveys. Inter Math Forum, 2(14): 675-687.

Zhu CJ, Hao ZC. 2009. Application of grey relation analysis in evaluation of water quality. Environ Sci Inform Applicat Technol, (1): 255-257. 